\title{
Effects of species differences on oocyte regulation of granulosa cell function
}

Jia Yi Lin, Janet L Pitman-Crawford, Adrian H Bibby, Norma L Hudson, C Joy Mclntosh, Jennifer L Juengel ${ }^{1}$ and Kenneth P McNatty

School of Biological Sciences, Victoria University of Wellington, Wellington 6140, New Zealand

${ }^{1}$ Centre for Reproduction and Genomics, Invermay Agricultural Centre, AgResearch Limited, Mosgiel 9053,

New Zealand

Correspondence should be addressed to K P McNatty; Email: kenneth.mcnatty@vuw.ac.nz

Reproduction (2013) $145 \times 1$

The author and journal apologize for an error in the above paper, which appeared in volume 144 part 5, pages 557-567. The error relates to the incorrect alignment of molecular weights on the $y$-axis of Figure 8 on page 562. The correct figure artwork appears here:

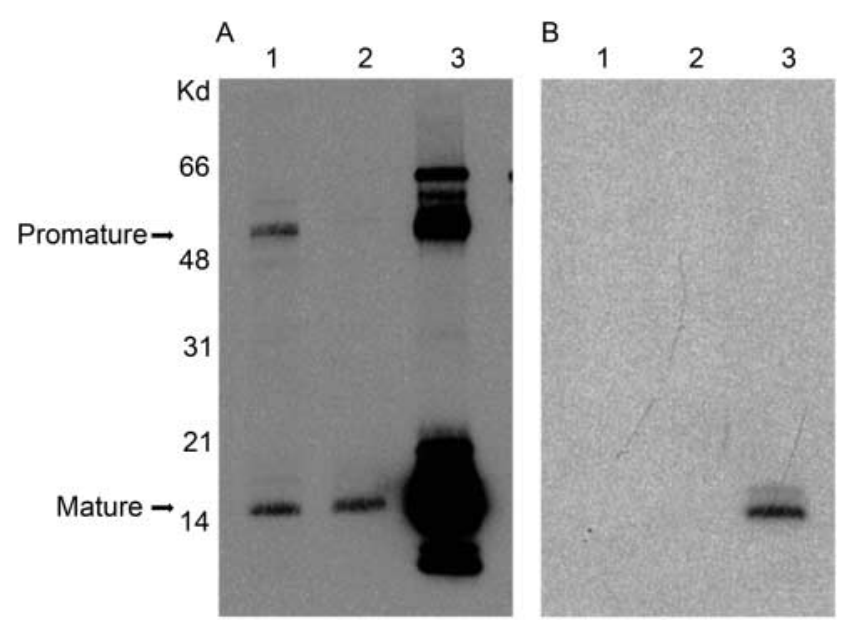

Figure 8 Western immunoblots of BMP15 in (A) ovine oocyte lysate and medium in which oocytes were incubated (incubation medium) and (B) after the BMP15 antibody (Mab61A) was preabsorbed with an ovine E. coli-derived BMP15 protein. Molecular sizes are indicated on the left of Fig. 7(A). Lanes are as follows: $1=$ oocyte lysate, $2=$ incubation medium and $3=293 \mathrm{H}$-produced ovine BMP15 as a positive control. 